\title{
Redes y conexiones: también un lugar para las mujeres. El caso Leonilda Barrancos en Chile, $1938-1945$
}

\section{Redes y conexiones: también un lugar para las mujeres. El caso Leonilda Barrancos en Chile, 1938-1945}

Dellavale, María Inés

María Inés Dellavale midellavale@hotmail.com Universidad Nacional de Córdoba, Argentina

\author{
Estudios Sociales. Revista Universitaria Semestral \\ Universidad Nacional del Litoral, Argentina \\ ISSN: 0327-4934 \\ ISSN-e: 2250-6950 \\ Periodicidad: Semestral \\ núm. 61, e0006, 2021 \\ estudiossociales@unl.edu.ar \\ Recepción: 01 Octubre 2020 \\ Aprobación: 30 Julio 2021
}

URL: http://portal.amelica.org/ameli/jatsRepo/293/2932743007/ index.html

DOI: https://doi.org/10.14409/es.2021.2.e0006

El contenido está bajo Licencia Creative Commons AtribuciónNoComercial-Compartir Igual 4.0 Internacional. Atribución - No Comercial - Compartir Igual (BY-NC-SA): no se permite un uso comercial de la obra original ni de las posibles obras derivadas, la distribución de las cuales se debe hacer con una licencia igual a la que regula la obra original.

\section{cc) (i) (2)}

Esta obra está bajo una Licencia Creative Commons AtribuciónCompartirIgual 4.0 Internacional.
Resumen: Este artículo se propone indagar sobre la estancia de Leonilda Barrancos (argentina nacida en Mercedes, provincia de Buenos Aires) en Chile entre 1938 y 1945. El eje estará puesto, por un lado, en las redes y conexiones construidas antes y durante este periplo, y por otro, en las facetas más destacadas de su vida pública. Allí se integró activamente al accionar del joven Partido Socialista -a través de la Acción de Mujeres Socialistas- y también se desempeñó como funcionaria en el Departamento de Horas Libres. Se analiza la pertenencia a un conjunto de sociabilidades consolidadas a partir del fenómeno de la Reforma Universitaria de 1918 y cómo las mismas le permitieron desempeñarse laboral y políticamente en aquel país.

Palabras clave: redes, mujeres, Partido Socialista Chileno, trabajadoras, es, Frente Popular.

\begin{abstract}
The purpose of this article is investigate about the stay of Leonilda Barrancos in Chile between 1938-1945. She was born in Argentine, in Mercedes province of Buenos Aires. This job will be focused on the one hand in the networks and connections built before and during this journey. On the other hand, in the most outstanding facets of her public life. In Chile she actively worked within the Young Socialist Party -though the Socialist Women's Action-. Also she worked as a civil servant at the Department of Free Hours. Furthermore it is analyzed how a set of consolidated sociabilities based on the 1918 University Reform phenomenon and how they allowed her to work politically and professionally in that country.
\end{abstract}

Keywords: networks, women's, Chilean Socialist Party, workers, Popular Front.

\section{Introducción}

Si en trabajos propios o que se refieren a ella hasta mediados de 1930, Leonilda Barrancos $^{[1]}$ aparecía a menudo con su apellido de casada, «de Bermann», y su 
derrotero estaba muy ligado al de su esposo Gregorio $^{[2]}$, a posteriori hay un corte definitivo, un camino que va construyendo sin ese vínculo y con unas relaciones nuevas y diferentes signadas por la política partidaria dentro del Partido Socialista Chileno. Pellegrini y Mosso (2017) describen la tridécada 1950-1980 como de ruptura del patrón de domesticidad aplicado y a su vez, adoptado por las mujeres. Pero la vida de Leonilda se inscribe en un período previo a esta consolidación, en realidad fue una pionera en la ruptura de estereotipos sexogenéricos, ella perteneció a una época en que todavía esos quiebres se mantenían en las sombras, sin atravesar las apariencias ni el nivel de lo implícito. No fue una disidencia proclamada ya que no encontramos alusiones de ese tipo en sus escritos, fue de hecho. La idea es ingresar en el plano de su subjetividad — tarea muy compleja por la limitación de las fuentes - analizando sus discursos y fundamentalmente sus prácticas ya que ellas ponen en evidencia una ruptura con los convencionalismos patriarcales.

Para acercarnos al entorno de Leonilda diremos que una compañera en el PS de Santiago de Chile, Carmen Lazo ${ }^{[3]}$, recuerda haberse alojado hacia fines de la década de 1930 con el objeto de recuperar su salud, en la que era entonces la casa y la clínica de Gregorio Bermann en Córdoba, y haber quedado agradablemente sorprendida por la multiplicidad de libros que allí encontró. Más que la biblioteca de un médico y hasta hacía poco de una pedagoga, por lo poco que comenta, era la biblioteca de intelectuales de amplias miradas, que leían de todo (Witker, 1993: 228). También en esa casa se recibían publicaciones diversas, entre ellas la revista Juventud y el periódico Claridad, ambas de la Federación de Estudiantes de Chile. ${ }^{[4]}$ Es muy probable que no faltaran muchas de las revistas que en la década de 1920 y 1930 circularon profusamente por Latinoamérica constituyendo un hilván que iría entretejiendo las relaciones y las amistades de quienes ya se sentían profundamente hermanados con una idea nada condescendiente con los colonialismos y los avances imperialistas del poderoso vecino del norte. No olvidamos que desde Córdoba Deodoro Roca lanzó su propio periódico Flecha de un contenido profundamente latinoamericanista. Pero lo que aquí nos interesa es ir encontrando eslabones que nos ayuden a justificar la elección de Leonilda por Chile luego de abandonar Córdoba. Otro indicio lo tenemos en una noticia de un diario cordobés que menciona el regreso a la ciudad del Dr. Bermann y su esposa e hijos de unas vacaciones en Chile en la década de $1930^{[5]}$. Vacacionar en Chile ¿tenía un significado más allá del descanso? ¿Conocían a Salvador Allende? Efectivamente existía una relación que ha sido mencionada por Sylvia Bermann, hija de Leonilda ${ }^{[6]}$. También es digno de mención que tanto Bermann como Allende compartían el campo profesional de la medicina con especial interés en la salud mental —en particular la relación existente entre esta y las poblaciones marginales lindando con la delincuencia - y ambos en sus épocas de estudiantes estuvieron vinculados al movimiento de la Reforma Universitaria en sus países. Otra coincidencia es que en 1933 el chileno participaba de la formación del Partido Socialista de Chile y Bermann era candidato a gobernador por una alianza del partido homónimo en Córdoba. Con estos ejemplos dejamos presentada a Leonilda Barrancos como integrante de esa intelectualidad involucrada abiertamente en la cuestión política. 
El objetivo del presente artículo se ancla en dos lugares interconectados entre sí: por un lado las vinculaciones, redes, de las que formaba parte Leonilda Barrancos que la llevaron a Chile para continuar un trabajo político que ya tenía un derrotero marcado en Argentina. Por otro, poder reflexionar acerca de los mecanismos puestos en juego por una mujer que toma la difícil decisión de mudarse a un país casi desconocido (no tenía allí familia), haciéndose cargo de una hija adolescente (desconocemos con quién permaneció su hijo Claudio), sin una posibilidad certera de desempeño laboral. En este punto nos preguntamos cuántas luchas internas debió tener Leonilda madre, Leonilda esposa o ex, Leonilda pedagoga, Leonilda política. Con este horizonte de interrogantes avanzamos en la tarea de mostrarla en un país que al parecer la recibió con mucho cariño y respeto permitiéndole consolidar justamente esas redes de las que ya había formado parte, pero ahora lo hacía sin su apellido de casada. «El pensamiento viene de afuera», dice Dora Barrancos (2017: 2) citando a Deleuze, «desearía que estas páginas pudieran poner en evidencia cómo los contextos hicieron sus operaciones, de qué modo burlaron mis concepciones y orientaron mis opciones». ¿Fue igual para su tía Leonilda? Pensamos que en su caso el contexto fue menos determinante, que ella tuvo más margen para las decisiones personales que le permitieron poner en juego una mayor agencia. Lo que nos parece importante demostrar es que la teoría de las redes nos va a permitir avizorar que ese núcleo inicial de relaciones que la llevó a elegir Chile, le permitió luego consolidar nuevos intercambios que la llevarían a otros recorridos latinoamericanos.

Para realizar este trabajo hemos hecho indagaciones utilizando diversas fuentes con metodologías propias de la historia: libros, documentos partidarios, artículos de diarios y revistas, algunos documentos oficiales ${ }^{[7]}$; esto se complementó con una especie de observación de campo que nos ha puesto en contacto con espacios reales y simbólicos transitados por Leonilda en el país trasandino.

\section{Las redes, la política, el género}

En este trabajo no ahondamos en ninguno de los términos de la tríada aludida en el título, simplemente queremos presentar esos aspectos en el sentido de una trama de fondo del accionar de Leonilda Barrancos.

Por ello no abordamos alguna red en particular de las muchas que se constituyeron en torno a las diversas temáticas que preocupaban y ocupaban a un amplio grupo de intelectuales ${ }^{[8]}$ latinoamericanos, sino que utilizamos la perspectiva de las redes para un análisis que se adentra en el subjetivismo de nuestro personaje y puede ayudarnos a entender este <andar por Latinoamérica> que comenzó para Leonilda Barrancos con su viaje y permanencia en Chile probablemente alrededor de 1937 o 1938. Tal como dice Pita González «las redes permiten observar las relaciones de solidaridad a través del intercambio de capitales culturales. Así, para entender en un momento dado las acciones de los individuos, es necesario comprender la relación de la persona en la estructura social; esto es, en la red en la que participa» (Pita González, 2016: 10). La profusa circulación de ideas a través de canales diversos como las revistas, las conferencias, los intercambios epistolares construían un espacio simbólico que superaba con creces los marcos geográficos del Estado nacional. A su vez esto permitía el 
establecimiento de una solidaridad que hubiese sido imposible por fuera de estas redes. Se fueron creando así espacios de intelección que compartían una serie de prácticas que permitían un enlace entre el campo intelectual y el campo político. Por parte de nuestro personaje, no hemos encontrado evidencia de actuación política partidaria hasta que arribó a Chile y allí se involucró de inmediato con el PS muy próxima a figuras encumbradas como Manuel Mandujano, Salvador Allende o Humberto Díaz Casanueva (Witker, 1993: 228).

Para este estudio un punto de partida es el de la Reforma Universitaria, que tuvo uno de sus momentos de mayor protagonismo en Córdoba en 1918 pero cuyo espíritu venía gestándose desde mucho antes y recorriendo gran parte de la geografía latinoamericana. Por lo que hemos revisado ${ }^{[9]}$, es casi una historia de hombres: eran quienes creaban periódicos y revistas, quienes presidían las diferentes agrupaciones, quienes usaban de la palabra en actos públicos, quienes se desplazaban en actos de difusión por diversos países y también quienes fueron más perseguidos y a veces debieron tomar el camino del exilio. Probablemente por su menor exposición y por estar en absoluta inferioridad numérica, el rol de las mujeres ha sido cubierto a menudo por la densa capa del olvido. Sin embargo, y en un proceso de larga data, está saliendo a luz el protagonismo femenino para ocupar el lugar que le corresponde, ni más ni menos, solo había que darle espacio.

Sin hacer alusión al género, Bergel dice de la Reforma Universitaria: «El hecho cordobés, en efecto, se quería a sí mismo tanto un producto como un anhelado dinamizador de una perspectiva latinoamericanista» (Bergel, 2008: 9). Y viéndolo en perspectiva, la Reforma fue uno de los acontecimientos de esa creciente tendencia a la hermandad latinoamericana que se incrementó en los comienzos del siglo XX pero que es de larga trayectoria. El mencionado autor recorre tres prácticas bastante comunes entre los gestores de ese «latinoamericanismo desde abajo»: los viajes, las cartas y las revistas de alcance continental. ¿Podríamos inscribir en este grupo a Leonilda Barrancos? De esos tres elementos en ella sólo encontramos los viajes, y aun así, los viajes que realiza, no comparten las características de los de un Vasconcelos, un Palacios o un Haya de la Torre, para nombrar solo algunos ${ }^{[10]}$. Sin embargo, si ella tuvo un lugar de pertenencia fue este grupo ampliado de intelectuales ligados a diversos quehaceres, pero unidos por intereses comunes.

Si bien la elección de su carrera en el ámbito de la docencia la inscribía en los estereotipos comunes a muchas de las jóvenes de su época, el hecho de tener que cursar en una de las pocas escuelas en Argentina que otorgaban habilitación para dar clases en el secundario, la Escuela Normal de Paraná, llevó a su padre a tener que optar por una beca ${ }^{[11]}$ y con ella a tener que alejarse del lugar de residencia e instalarse en otra ciudad. Ya instalada en Buenos Aires y ejerciendo la docencia, formó parte de la Liga Racionalista Argentina; en Córdoba perteneció al «Comité de socorro a las víctimas del hambre en Rusia» (1922), integró grupos que protestaron airadamente por la deportación del exiliado boliviano Tristán Marof (1936) y participó en el Comité de Ayuda al Pueblo Español (1936). También podríamos mencionar que en ocasión de una conferencia dictada en Santiago del Estero aparece rodeada de figuras ligadas al grupo La Brasa que trabajaba por la difusión de la cultura local (Dellavale, 2016). Coincidimos en que: 
«los intelectuales se vinculan a través de amistad y camaradería [...] Si bien existe un intercambio de bienes culturales (publicaciones), capitales simbólicos (ideas) y favores, es más difícil señalar qué aportó cada uno y con qué regularidad. [El estudio] de redes se concentra en reconstruir los vínculos que existieron al interior de un grupo, o entre un conjunto de individuos, instituciones u organizaciones, para explicar cómo se conformaron y de qué forma, al agruparse, influyeron en un momento histórico» (Pita González, 2016: 9).

\section{La lucha de las mujeres chilenas}

Ya hemos mencionado que es muy probable que a la hora de tomar la decisión de irse a Chile, pesaran para Leonilda razones que tenían origen en su propia subjetividad, en su situación personal y no en el estado de situación del país de acogida. No obstante, y dada su inmediata inserción en el mundo laboral ligado a la política, se hace necesaria una breve reseña que nos acerque al mundo de la mujer chilena, ámbito al que ella se incorporó de inmediato.

Navarro López (2016) ha estudiado la presencia femenina en el Partido Obrero Socialista (POS) de Chile entre 1912 y 1922, donde habla de la incidencia muy marcada del dirigente Recabarren en pos de dicha integración. A pesar de ese reconocimiento, la inclusión de la mujer en las actividades partidarias fue escasa y contó con poco aliento desde la dirigencia masculina. El autor plantea diferencias en los discursos relacionados con la actividad femenina entre el norte salitrero -haciendo hincapié en el anticlericalismo y colocando a la mujer en un rol complementario- y las ciudades de Santiago y Valparaíso, adquiriendo en las zonas urbanas un abanico más amplio de reivindicaciones e intereses tomando distancia del rol patriarcalmente impuesto. Esta tendencia se acentúa hacia el final de la segunda década del siglo XX en que se asiste a un protagonismo de la mujer no sólo mayor sino también cualitativamente diferente: se percibe más autonomía gremial y política y una profundización de los temas específicos como la denuncia del patriarcado, la falta de derechos políticos, la sobrecarga de exigencias por las tareas domésticas, es decir, hay un abierto posicionamiento de género.

A pesar de estos marcados avances, cuyas reseñas aquí se limitan a trabajos realizados dentro del POS, la conquista de derechos de las mujeres fue muy lenta; para poner solo un ejemplo digamos que en 1934 se logró la incorporación del voto femenino en las elecciones municipales ${ }^{[12]}$ pero recién en 1949 una ley habilitó dicha posibilidad para la elección de presidente y las parlamentarias. Esta presencia femenina dentro del POS continuó cuando ese partido devino en Partido Comunista de Chile PCCh.

La notable feminista e historiadora del feminismo, la socióloga Julieta Kirkwood $(1986: 107,113,114)$ reflexiona largamente acerca de la irrupción de las mujeres en la vida pública chilena, incluyendo la política-aunque antipartido-, pero también se pregunta sobre los silencios de largos períodos. Para nuestra complacencia, la época que aquí estamos analizando coincide con un lapso de ascenso en esa participación que será seguido de un reflujo posterior a la consecución del voto femenino. La autora narra críticamente el rol de este feminismo como «erradicador de vicios», «liberador de lacras sociales» estableciendo una dicotomía entre hombres y mujeres donde los primeros son los portadores del vicio y las segundas el resguardo de una sociedad 
más ordenada atribuyéndole «cualidades mesiánicas, depuradoras a la acción <incontaminada > de las mujeres en la política».

También Montero (2017) habla de una consolidación en la década de 1930 del movimiento feminista chileno con un repertorio de manifestaciones diversas como revistas, actividades callejeras, elaboración de proyectos de ley y participación en redes internacionales que las llevaron a trabajar por la paz, en contra del fascismo y en favor de República Española. Su investigación se centra particularmente en la incidencia que el discurso feminista en aquella nobel república tuvo en Chile, concretamente manifiesta: «Mi argumento es que las ideas que surgen en la España republicana sobre el rol de las mujeres en la sociedad se transformaron en insumos que aportaron a la consolidación del feminismo en Chile» (Montero, 2017: 778). Menciona tres movimientos con sus especificidades y la difusión de sus planteos a través de la prensa: el Partido Cívico Femenino, el Movimiento Pro-Emancipación de las Mujeres de Chile $(\mathrm{MEMCH})$ y la Unión Femenina de Chile. Cada organización difundía su ideario a través de una prensa caracterizada por su politización no partidista y que daba cuenta de la polarización y efervescencia del momento.

Rojas Mira C. (2012) rescata los temas abordados por las anteriores historiadoras. Desarrolla la idea de que una vez conseguido el derecho al voto que las había cohesionado en su lucha hasta ese momento, y posterior a las primeras elecciones presidenciales en que participaron en 1952, las mujeres chilenas continuaron militando en los partidos políticos, pero atomizando las demandas debido a que se trataba de representantes de diferentes sectores sociales en cuanto a necesidades y aspiraciones (Rojas Mira, 2012: 339). Se detiene en el hecho de que la formación de agrupaciones femeninas dentro de los partidos, contribuyó a afianzar el rol tradicional femenino de cuidado, bienestar familiar y solidaridad. Así, esto contribuyó a la subordinación de las mujeres a los dictados masculinos dejando a estas al margen de las grandes decisiones de la política partidaria, convirtiéndolas, en fin, en militantes de segunda categoría (Rojas Mira, 2012: 341). Curiosamente, ninguna de las autoras mencionadas hace referencia a la Acción de Mujeres Socialistas (AMS), agrupación surgida en el seno del PS como se verá seguidamente.

Dos trabajos aparecidos en el último bienio han venido a traer a un primer plano la figura de Leonilda Barrancos; ambos han sido valiosos y una importante guía en cuanto a la consulta de fuentes: uno es «Mujeres socialistas. Protagonistas de una historia ${ }^{[13]}$ que se propone llenar un vacío y hacer justicia respecto del reconocimiento de la labor de las mujeres socialistas participantes en ese partido en Chile desde el momento mismo de su fundación en 1933. Se trata de una investigación llevada a cabo por iniciativa de la Vicepresidencia de la Mujer del PSCh trabajando con un equipo especializado. El otro trabajo al que hago alusión es el publicado en Córdoba por la Revista Etcétera bajo el formato de Conversa, en este caso con Dora Barrancos, sobrina de Leonilda. La propuesta apunta a rescatar a esta como una figura de la Reforma de 1918. En ese sentido coincidimos en que ella estaba habitada por el espíritu reformista. 


\section{Incorporación de Leonilda Barrancos a la actividad pública chilena}

Así, Leonilda Barrancos llegó a Chile en un momento de efervescencia en cuanto a la movilización de las mujeres. En esa avanzada década de 1930, estaban dadas las condiciones de posibilidad para la lucha femenina ya que una de las promesas electorales del candidato a presidente por el Frente Popular ${ }^{[14]}$, y ganador de las elecciones, fue otorgar a las mujeres la legislación que les permitiera participar en las contiendas electorales. La enfermedad y muerte del presidente haría que el proyecto fuese aplazado por varios años.

Como se dijo, una de las primeras actividades de Leonilda fue su participación en la AMS. La misma surgió en 1935 con destacadas militantes como Blanca Flores Alfaro, María Montalva o Violeta de la Cruz Tapia que dirigió, tiempo después, Camarada, la revista de este organismo partidario (Witker, 1993: 219). La mencionada agrupación se constituyó formalmente a partir del IV Congreso Nacional del Partido Socialista. En el diario La Opinión, que se auto proclamaba independiente, no hemos encontrado ninguna mención a la actividad de la AMS, espacio que sí tenía, aunque escueto, la Federación Juvenil Socialista. Por suerte nos ha quedado como fuente el «Reglamento de organización de la Acción de Mujeres Socialistas» ${ }^{[15]}$ donde observamos un claro posicionamiento político partidario, clasista, pero a su vez una perspectiva de género desde la introducción que hace María Montalva: «Todas sabemos que la emancipación femenina está íntimamente ligada a la emancipación del proletariado (...) hemos tomado ya un puesto de combate en las luchas sociales (...) en defensa de la colectividad, de nuestros intereses de clase y muy especialmente de los derechos de nuestro sexo...» (Reglamento de organización de la Acción de Mujeres Socialistas, 1939: 3). La AMS agrupaba a las Brigadas Femeninas Socialistas, conjunto de secciones femeninas adultas y juveniles distribuidas en todo el país. La dirección recaía en la Secretaría Nacional designada por el Comité Central y dependiente del mismo, la cual contaría con el asesoramiento de cuatro militantes: dos adultas y dos juveniles. A su vez en cada provincia habría una secretaria regional. Como se dijo antes, corrían en paralelo las dos perspectivas mencionadas, la de género «la distribución de edades no debe tener importancia porque lo que pesa es el sexo» (Reglamento de organización, 1939: 8), y la política partidaria «hemos ingresado al Partido Socialista por considerarlo el único Partido popular que defiende con valentía dentro de la realidad chilena nuestro Presente y nuestro Porvenir» (Reglamento de organización, 1939: 3). Una de las proposiciones que se hacía la agrupación era la de ser una escuela donde por medio de charlas, cursos de orientación doctrinaria y lecturas comentadas se capacitara a las mujeres socialistas para enfrentarse con éxito a los problemas económico sociales y a las luchas que permanentemente debe sostener por la conquista de las reivindicaciones femeninas (Reglamento de organización, 1939: 8). Al igual que el resto de las agrupaciones del partido, la AMS debía tener su uniforme para los actos oficiales del partido y para desfiles y también su estandarte.

Leonilda Barrancos estuvo muy cerca de esta agrupación, pero nos atrevemos a afirmar que sin formar parte de las Brigadas Femeninas, tal vez por su condición de extranjera. Aparece en varias fotografías en la bibliografía citada, siempre en compañía de dirigentes tanto femeninas como masculinos y su presencia se 
relaciona con el dictado de charlas y conferencias; es muy probable que formara parte de la mencionada escuela de capacitación de la AMS. En el comentario citado anteriormente, Carmen Lazo, la menciona haciendo «un gran aporte a la formación cultural de las mujeres socialistas que veníamos despertando a la política. Dio conferencias, escribió artículos y sobre todo, nos enseñó mucho en el grupo de compañeras; no solo trabajó con las mujeres, también en los sindicatos y barrios populares» (Witker, 1993: 228).

Acerca de las mujeres escribió un informe presentado ante el Congreso Nacional de la Conferencia de Trabajadores y que fuera publicado en la Revista Socialista de la ciudad de Buenos Aires de agosto de 1939. En el mismo, titulado «Condición social de la mujer en Chile», hay un posicionamiento en defensa de la mujer, aunque sin aludir nunca al feminismo. Desde el comienzo, Leonilda recupera el recuerdo de la Asociación Internacional de Mujeres de cuyo primer Congreso se habían cumplido recientemente cincuenta años. A continuación menciona un hecho que no era común que fuese abordado cual es la capacidad de la mujer para reemplazar al hombre en diversas tareas que hasta el momento solo a éste le estaban reservadas ${ }^{[16]}$, advirtiendo que estos roles femeninos habían sido asumidos de hecho sin llegar a ser incorporados a los Estatutos. También alude a la ruptura de clase cuando dice: «Esta desigualdad jurídica [respecto de los hombres] agudiza, para la mujer obrera los problemas de clase y condiciona un estado social, cultural y psicológico de menor-valía que pesa negativamente en las luchas del proletariado» (Revista Socialista, 1939: 90). Hablando específicamente de Chile, nunca separa la condición de vida de las mujeres de las del proletariado, recalcando sí que los males que aquejan a este sector social, se agravan cuando se trata de mujeres. La morbilidad y mortalidad, la desnutrición, la insuficiencia física son males que aquejan a la Nación, pero se agravan en las mujeres porque siempre sus salarios son notablemente más bajos que los de los hombres. Esto abarca a las actividades productivas y al comercio y se profundiza en la condición de la mujer campesina. No omite explayarse en el desgaste físico que importaba la prolongación de la jornada de trabajo femenina con todas las tareas del hogar y el cuidado de los niños. Al momento de realizar proposiciones, el lenguaje adquiere un tono abarcativo de las realidades internacionales adhiriendo a las propuestas de la vieja luchadora feminista uruguaya Paulina Luisi, lo que deja entrever que así como las condiciones de inferioridad a la que estaban sometidas las mujeres no eran exclusivas de Chile, tampoco lo eran las soluciones (Revista Socialista, 1939:94). El artículo pareciera anclar en el caso de Chile solo a modo de ejemplo, en realidad todo el tiempo alude a la condición de la mujer trabajadora en general, y por tanto las soluciones también son proposiciones de orden general para cualquier lugar del mundo. En esta tesitura proponía «a) Bregar por el Estatuto de la Mujer; b) Propender a su cultura general y especializada. Para la última crear escuelas técnicas de aprendices». Proponía a ese Congreso

«la formación de un Comité de mujeres anexo a la CTCh (Central de Trabajadores de Chile) que a semejanza del Comité Internacional, reuniría todos los antecedentes nacionales y extranjeros sobre legislación y trabajo femenino, que estudie el desarrollo alcanzado por sus actividades, la situación económica, cultural y moral de la obrera, su lugar en las luchas de clase y proyecte un plan de acción a cumplir por las mujeres, para mujeres» (Revista Socialista, 1939: 96). 
Yendo de lo general a lo particular recomendaba:

«Realicen nuestros camaradas en sus casas, en las fábricas, en todas partes, con sus compañeras, hijas y hermanas, labor concorde con un mundo mejor; valorice a la mujer, preocúpense de vincularla al Sindicato, a la comprensión de los grandes problemas que agitan al mundo, a su país y a su hora y habrán hecho también en este orden verdadera democracia» (Revista Socialista, 1939: 97).

Ella continuaba poniendo como ejemplo lo ocurrido en la Comuna Socialista de Viena ${ }^{[17]}$ a lo que agregaba el caso de Rusia: «Señalamos el ejemplo de Rusia y Viena a nuestros camaradas para que sus reclamos se sientan fortalecidos dentro de parejos ideales con idéntica ejemplaridad» (Revista Socialista, 1939: 93).

Otro aporte importante que hizo Leonilda en Chile fue su desempeño al frente del Departamento de Horas Libres dependiente de la Caja del Seguro Obligatorio $^{[18]}$, que estaba bajo la órbita del Ministerio de Salubridad. Salvador Allende tuvo a su cargo dicho Ministerio entre fines de septiembre de 1939 y abril de 1942. En su primer discurso como tal, finalizó con estas consignas: «Haré realidad el viejo y sentido deseo de nuestro Partido. ¡Aire y sol para los niños de los trabajadores! ¡Vacaciones para obreros y obreras! ¡Contra el tugurio, el prostíbulo y el juego! Montaña y mar» ${ }^{[19]}$. Yáñez Andrade (2020) hace una revisión muy completa sobre cómo la temática del ocio, el tiempo libre y el turismo han entrado en el campo de los estudios históricos bastante tardíamente y lo han hecho especialmente de la mano de la nueva historia social inglesa con Hobsbawm y Thompson. El autor repasa menciones bibliográficas de abordaje de estos temas desde una perspectiva sociocultural, política y económica centrándose especialmente en el rol del Estado y de los empresarios. En ese sentido busca identificar las principales líneas de investigación que han marcado los estudios sobre las prácticas recreativas «(...) en el mundo laboral latinoamericano entre los años 1930 y 1950, complementando los enfoques nacionales con los transnacionales» (Yáñez Andrade, 2020: 1897). Traemos a colación este artículo para poner en evidencia que la preocupación por los usos del tiempo libre, en especial de los trabajadores, fue un fenómeno generalizado en la época que estamos abordando y que coincidió con la obtención de derechos como el descanso semanal y las vacaciones pagas.

Justamente, desde el desempeño en el cargo mencionado, Leonilda publica un artículo titulado Horas Libres y Vacaciones. ${ }^{[20]}$ Advertimos allí una concepción estructurada, dirigista, de como debía orientarse a los trabajadores para el aprovechamiento de su tiempo libre. A través del Departamento de Horas Libres que ella dirigía se había creado la primera Misión de Cultura que organizaba cursos y talleres relacionados con las más diversas temáticas como «clases de canto, solfeo, violín, guitarra, estudiantina, arte teatral y declamación, educación física, sociología, agricultura, floricultura, labores, tejido a mano y a máquina, telares, bordados» (Barrancos 1939b: 3), habiendo sido asistidos por el Departamento de Educación Sanitaria. La orientación estructurante, que para nada se ocultaba, tendía a realizar una labor planificada, con objetivos claros, con coordinación entre diferentes instituciones organizadoras y evitando que esos lugares se convirtieran en «centros de entretenimientos banales, cuando no negativos para el trabajador, propicio al fomento de hábitos nocivos, como el alcoholismo, o la dilapidación en esparcimientos insubstanciales de energías 
que el Estado debe orientar hacia más altos fines (...)» (Barrancos, 1939b: 3). Resaltaba la necesidad de no dejar estas labores libradas a la buena voluntad de nadie, sino encomendarla a «técnicos y maestros imbuidos de fervor social, de espíritu solidario; con calidad de líderes». Tampoco podría la misma ser fructífera si no se enmarcaba dentro de un plan general que tuviese continuidad:

«En ningún nuevo grupo de casas para obreros puede faltar ya un Centro Social donde se impartan, en las Horas Libres del asalariado, conocimientos que le mejoren como tal, que creen vínculos de solidaridad, que muestren y aclaren los problemas de su clase, despertando también su conciencia de clase, que le liguen a un desarrollo cultural y lo vinculen a un otro sentido de la nacionalidad que se está realizando» (Barrancos, 1939b: 3).

Pasaba a exponer luego el plan de trabajo que tenía con otros organismos del Estado y con los sindicatos que abarcaban desde un Teatro del Pueblo hasta colonias de vacaciones en diferentes lugares del país de los que desconocemos si pudieron llevarse a cabo.

Respecto de la labor dentro del PS de Chile la figura de Leonilda fue adquiriendo una relevancia cada vez mayor que deducimos de su participación en algunos Congresos partidarios. Eran momentos de gran tensión dentro del partido, con fuertes discrepancias internas debido a la participación en el gobierno del Frente Popular donde se daba una enconada disputa entre sectores conservadores y de izquierda. Esto quedó de manifiesto en el VI Congreso de fines de 1939 donde se planteó el rompimiento de un grupo disconforme con la forma en que se estaba desenvolviendo el partido en las áreas de gobierno. A raíz de esta ruptura se convocó a un Congreso Extraordinario en Curicó en mayo de $1940 \mathrm{al}$ que asistieron dirigentes de otros países latinoamericanos como

«el diputado señor Ghioldi Secretario General del Partido Socialista de Argentina, Luis Alberto Sánchez y Manuel Seoane jefes del partido aprista de Perú, Rómulo Betancourt del Partido Democrático de Venezuela, Emilio Frugone jefe del Partido Socialista de Uruguay [y, para destacar, dos mujeres] Leonilda Barrancos dirigente del socialismo de Argentina y Fanay Simon delegada y corresponsal del Partido Socialista de los EE UU» ${ }^{[21]}$.

Además de los temas internos y particulares del partido, se abordó la situación internacional de una extrema tensión por la guerra en Europa desatada desde 1939 vista como un enfrentamiento entre el fascismo y la democracia. En esta tesitura se toma la resolución de convocar a un Congreso de Partidos Populares y Democráticos de América Latina para discutir y eventualmente acordar una postura común.

Los/as encargados/as de la organización del evento fueron Juan Garafulic, del PS de Chile, Rómulo Betancourt por Venezuela, Magda Portal ${ }^{[22]}$ por el aprismo peruano y Leonilda Barrancos por el PS de Argentina.

«Se invitó a los partidos populares y democráticos de América Latina, socialistas o no, que empuñaban la bandera antifascista y de liberación americana [...]. No fueron invitados los partidos comunistas porque ellos tenían puntualizada su acción internacional común, en conformidad a las decisiones de sus autoridades» (Jobet, 1965: 45).

Asistieron delegaciones de Argentina, Bolivia, Ecuador, México, Panamá, Perú, Uruguay, Venezuela y Chile y se obtuvo la adhesión de otros partidos entre 
los que estaba el radical de Argentina. No es objeto de este trabajo abordar los temas de este Congreso pero sí lo hemos mencionado para destacar por un lado la casi total ausencia femenina en las delegaciones y, lo más importante, la presencia en la organización tanto de Leonilda Barrancos como de la poeta Magda Portal, lo que da una idea de la dimensión enorme que ambas habían alcanzado.

Según Tarcus (2007: 48), Barrancos también fue partícipe del IX Congreso Ordinario celebrado en Rancagua en enero de 1943 donde un sector planteaba una acerba crítica a la participación de los socialistas en el gobierno de Ríos en que las propuestas del partido quedaban eclipsadas todo el tiempo. Salvador Allende sostenía la tesitura de abandonar dicha participación en contra del líder Marmaduke Grove que fue desplazado haciéndose cargo Allende de la Secretaría General. Finalmente, la decisión de alejarse de la coalición gubernamental fue tomada en el IV Congreso Extraordinario reunido en Valparaíso en agosto de $1943^{[23]}$.

En determinados años Leonilda se incorporó al grupo de profesores que dictaban los Cursos de Temporada que organizaba la Universidad de Chile a partir de 1936 desde su Departamento de Extensión Universitaria. En la Memoria de Diez años de labor (1945) ha quedado plasmada una amplia información acerca de los mismos. Los había de dos tipos: de Verano y de Invierno con la particularidad de que, al recibir subsidio del Ministerio de Relaciones Exteriores, ofreció becas a estudiantes de todos los países del continente.

$$
\begin{aligned}
& \text { «(..) una labor americanista en que han colaborado notables profesores, chilenos y } \\
& \text { extranjeros, y estudiantes venidos de todos los países de este hemisferio. En sus aulas } \\
& \text { se han reunido, como en un congreso abierto, para conocerse, abrazar y ventilar sus } \\
& \text { problemas, al amparo de un ambiente de fraternidad y de amplia tolerancia que les } \\
& \text { ha brindado la República y la tradición de nuestra Casa Universitaria» (Diez años } \\
& \text { de labor, 1945: 8). }
\end{aligned}
$$

Estos cursos contaron con la colaboración de, entre otros, el Ministerio de Salubridad y numerosos organismos del estado como la Caja del Seguro Obligatorio. Los dictados por Leonilda fueron: «Principios de Oratoria» y «Los valores en filosofía, psicología y pedagogía» en 1944; «Introducción a la Filosofía con relación a la enseñanza»y «Arte de la palabra en público» en 1945 (p. 70). En lo que respecta a nuestra investigación, esta es la última noticia que hemos encontrado relacionada con la vida pública de Leonilda en Chile.

De su vida privada solo tenemos algunos recortes, como por ejemplo que estuvo acompañada por su hija Sylvia Bermann. Ésta tuvo un importante acercamiento a la Juventud Socialista, pero abandonó aquel país para volver a Argentina en 1943, cuando su padre Gregorio fue encarcelado. Por otra parte, cierta bibliografía consultada como Witker (1993), Lugones, Díaz y Romero (2018) o Mujeres Socialistas. Protagonistas... (2018), la muestran en diversos actos públicos, siempre rodeada de quienes eran sus compañeras/os de ruta en ese momento. 


\section{Consideraciones finales}

Tal vez, la palabra «intelectual» no sea lo suficientemente inclusiva del mundo de realidades, expectativas, intereses y necesidades de nuestro personaje; podríamos completarlo diciendo que fue pedagoga, militante de ideas socialistas, defensora de los derechos de las mujeres, profundamente latinoamericanista y preocupada por las realidades sociales de nuestros países.

Las actividades desarrolladas en Chile por Leonilda Barrancos tienen dos vertientes a destacar que abrevan en sus ideas socialistas: una actuación partidaria, militando dentro del Partido Socialista y, por otro lado, su desempeño como funcionaria en dependencias estatales. Ambas están imbricadas y dan cuenta de una gran capacidad de trabajo. Asimismo, por algunos testimonios aislados y por la documentación y bibliografía consultada, sabemos de su alternancia con personalidades de otros países con quienes mantuvo vínculos que seguramente trascendieron lo político. Tal lo ocurrido con Magda Portal, poeta peruana integrante de la Alianza Popular Revolucionaria Americana (APRA), con quien compartió la tarea de organizar el Congreso de Partidos Populares y Democráticos de América Latina como se mencionó ut supra. Por esos años también se relacionó con el partido Acción Democrática de Venezuela, donde luego fue invitada por Rómulo Gallegos en su corta presidencia. La pertenencia a este mundo de sociabilidades político-ideológicas colaboró determinando algunas decisiones de su vida personal, como la de trasladarse primero a trabajar a Chile donde luego se le abrieron nuevas oportunidades de viajes: esto nos permite afirmar que, en este particular, la pertenencia a la red fue instituyente.

En fin, hemos tratado de reseñar la estancia de Leonilda en Chile, pero su «viaje» había comenzado mucho antes y se prolongaría hasta el fin de sus días, sus viajes reales existieron, pero también sus viajes simbólicos que tuvieron siempre como norte la lucha por una vida mejor para nuestros pueblos.

\section{Referencias}

BARRANCOS, DORA (2017): «Mi recorrido hasta la historiografía de las mujeres», Revista Descentradas, vol 1, 1, marzo de 2017.

BARRANCOS, LEONILDA (1939a): "Horas libres y vacaciones", Acción Social, 84, Santiago de Chile.

BARRANCOS, LEONILDA (1939b): "Condición social de la mujer en Chile”, Revista Socialista, Año X, 111, Buenos Aires.

BERGEL, MARTÍN (2008): «Latinoamérica desde abajo. Las redes trasnacionales de la Reforma Universitaria (1918-1930)», en La Reforma Universitaria: desafios y perspectivas noventa años después, Buenos Aires, CLACSO. Recuperado de http:/ /bibliotecavirtual.clacso.org.ar/clacso/gt/20101109082604/17bergel.pdf

BERGEL, MARTÍN (2018) (coord.): Los viajes latinoamericanos de la Reforma Universitaria, Rosario, Humanidades y Artes Ediciones.

BOLÍVAR MEZA, ROSENDO (2002): «Un acercamiento a la definición de intelectual», en Estudios Políticos, 30, sexta época, mayo-agosto. Recuperado de h ttp://www.revistas.unam.mx/index.php/rep/article/view/37544

DELLAVALE, MARÍA INÉS (2016): «Leonilda Barrancos: un aporte a la irrupción de las mujeres en la cuestión pública en Córdoba (1921- alrededor de 1936)», 
presentado en las Primeras Jornadas Nacionales de la Red de Estudios sobre el Socialismo Argentino (RESA), realizadas en Buenos Aires el 14 y 15 de diciembre de 2016.

DIARIO LA OPINIÓN (1938). Consulta a diferentes períodos. Santiago de Chile.

DIARIO LA OPINIÓN (1943). Consulta a diferentes períodos. Santiago de Chile.

DIARIO LA VOZ DEL INTERIOR (1920). Consulta a números aislados. Córdoba, República Argentina.

DIARIO LA VOZ DEL INTERIOR (1930). Consulta a números aislados. Córdoba, República Argentina.

DIEZ AÑOS DE LABOR (sin autor/a, 1945) Santiago, Universidad de Chile. Departamento de Extensión Universitaria. Escuelas de Temporada.

Estatuto y Reglamento del Partido Socialista (1939). Reglamento de Organización de la Acción de Mujeres Socialistas, Imprenta Darricarrere.

FITÓ, JOSÉ LUIS (2020): «Gregorio Bermann. Reformista, pensador y Psiquiatra». Recuperado de http://www.polemos.com.ar/docs/temas/Temas6/1\%AA\%20pa rte\%20Gregorio\%20Bermann.htm

JOBET, JULIO CÉSAR (1965): El socialismo chileno a través de sus Congresos. Santiago de Chile, Editorial Prensa Latinoamericana SA.

KIRKWOOD, JULIETA (1986): Ser politica en Chile. Las feministas y los partidos. Santiago de Chile, Facultad Latinoamericana de Ciencias Sociales.

LUGONES, MARÍA GABRIELA; DÍAZ, MARÍA CECILIA; ROMERO, SANTIAGO MANUEL (2018): «Leonilda Barrancos: una embajadora reformista. Semblanza y entrevista con Dora Barrancos», Etcétera. Revista del Area de Ciencias Sociales del CIFFyH, 3. Córdoba, UNC. Recuperado de: https:/ /revistas.unc.edu.ar/index.php/etcetera/article/view/22597

MONTERO CLAUDIA (2017): «El discurso feminista en Chile y las imágenes de la mujer en la República Española». Revista Estudos Feministasa, vol.25, núm. 2, mayo-agosto, 2017, pp 777-801. Universidade Federal de Santa Catarina, Brasil.

MUJERES SOCIALISTAS. PROTAGONISTAS DE UNA HISTORIA (2018): Vicepresidencia de la Mujer, Partido Socialista de Chile, s/d.

NAVARRO LÓPEZ, JORGE (2016): «El lugar de la mujer en el Partido Obrero Socialista de Chile (1912-1922)», en Izquierdas, 28, Santiago

PELLEGRINI MALPIEDI, MICAELA; MOSSO, AGUSTINA (2017): «Entre hermanas, entre mujeres: la vida cotidiana de Olga y Leticia Cossettini, Argentina, 1950 - 1980», en, Arenal, 24:2; julio - diciembre, Editorial Universidad de Granada.

PITA GONZÁLEZ, ALEXANDRA (2016) (comp.): Redes intelectuales transnacionales en América Latina durante la entreguerra. Universidad de Colima, México, 2016.

REVISTA ACCIÓN SOCIAL (1939), Santiago de Chile, consultado por última vez el 26/02/2019 en http://www.memoriachilena.gob.cl/602/w3-article-75950.html

REVISTA SOCIALISTA (1939), Año X, Núm. 111, agosto de 1939. Buenos Aires, Editorial La Vanguardia.

REVISTA DIGITAL CONTRABANDO (2006). «Silvia Bermann: Itinerarios de una revolucionaria», entrevista del 30/09/2006.

ROJAS MIRA, CLAUDIA (2012): «¿Mujeres comunistas o Comunistas mujeres? Segunda mitad del siglo $\mathrm{XX}$, en ULLIANOVA, OLGA; LOYOLA, MANUEL; ÁLVAREZ, ROLANDO (ed.) 1912-2012. El siglo de los comunistas 
chilenos. Santiago de Chile. Instituto de Estudios Avanzados. Universidad de Santiago de Chile.

TARCUS, HORACIO (2007): Diccionario biográfico de la izquierda argentina, Buenos Aires, Emecé Editores S.A., 2007.

WITKER, ALEJANDRO (comp.) (1993): Historia documental del PSCH 1933-1993, Concepción, Instituto Latinoamericano de Concepción. Consultado el 20/12/2019 en http://www.memoriachilena.gob.cl/602/w3-article-8103.htm 1

YÁÑEZ ANDRADE, JUAN CARLOS (2020): «Trabajadores y prácticas recreativas. Otra mirada al mundo del trabajo en América Latina (1930-1950)», en Izquierdas, 49, diciembre 2020: 1895-1911.

\section{Notas}

[1] Leonilda Barrancos nació en Mercedes, provincia de Buenos Aires el 12 de febrero de 1890. La fecha del nacimiento ha sido tomada de la partida respectiva que se encuentra archivada en la Escuela Normal de Paraná actual Escuela Normal Superior José María Torres; hay autores como Tarcus (2007) que mencionan solamente el año 1892. Terminó sus estudios en aquella institución cuyo título la habilitaba para desempeñarse como profesora en escuelas de nivel medio. Desde el comienzo de sus actividades laborales, ya en Buenos Aires, se manifestó como una docente comprometida con las nuevas tendencias pedagógicas, la llamada Escuela Nueva o escolanovismo, siendo uno de sus principales referentes el maestro Julio Barcos. También estuvo habitada por las ideas transformadoras de la Reforma Universitaria de 1918, participando en alguno de sus acontecimientos (Lugones, Díaz y Romero, 2018).

[2] Gregorio Bermann (1894-1972) fue un médico graduado en la Universidad Nacional de Buenos Aires que se dedicó a la psiquiatría llegando a ser reconocido nacional e internacionalmente. También siguió la carrera de Filosofía en la misma universidad. Fue un activo impulsor de la Reforma Universitaria de 1918 siendo ese año electo delegado a la Asamblea estudiantil de Córdoba. En 1921, ya casado con Leonilda Barrancos, se radicó en Córdoba donde se desempeñó como docente universitario en la cátedra de Medicina Legal y Toxicología. En 1936 el matrimonio se divorció tomando cada uno su propio derrotero (Fitó, 2020)

[3] Carmen Lazo fue una militante socialista desde su juventud llegando a ser junto a Laura Allende las dos primeras mujeres diputadas por el PS.

[4] La Voz del Interior, 28 de noviembre de 1921.

[5] Cabe aclarar que Bermann había asistido al Congreso Internacional del Trabajo y participó en el Congreso Médico Gremial. Artículo probablemente de La Voz del Interior, sin fecha, Archivo Bermann.

[6]Dato obtenido de la biografía de Sylvia Bermann en Museo Casa de la Reforma Universitaria en https://reformadel18.unc.edu.ar/sylvia-bermann/

[7] Hubiese sido de gran valor acceder a documentación personal como cartas, manuscritos, tarjetas, etc. pero fue infructuosa la búsqueda. Seguramente contribuye a ello los múltiples traslados con cambio de residencia entre países que tuvo Leonilda.

[8] Al hablar de intelectuales queremos significar a un grupo de individuos que producen y administran contenidos culturales representativos de la sociedad en que se desenvuelven. Algunas características distintivas serían: capacidad de reflexión, pensamiento independiente con ruptura de estereotipos, agencia innovadora. Son producto de la sociedad en que se desenvuelven pero con talento para mirarla críticamente, para ponerla en duda, para plantear cambios (Bolívar Meza, 2002). 
[9]Bergel (2008), Pita González (2016), para mencionar lo consultado en este trabajo, pero la bibliografía sobre la Reforma y sus derivas es inmensa.

[10]Bergel (2018) reúne una serie de trabajos acerca de los viajes de los reformistas latinoamericanos. Si, como dice Pita González, el estudio «de redes se concentra en reconstruir los vínculos que existieron al interior de un grupo, o entre un conjunto de individuos, instituciones u organizaciones, para explicar cómo se conformaron y de qué forma, al agruparse, influyeron en un momento histórico» (Pita González, 2016: 9), podríamos decir que este es un intento de adentrarnos en la trama de una red formada por intelectuales latinoamericanos de la que Leonilda Barrancos formó parte. Viajes con «pluralidad de sentidos», poniendo en evidencia el anhelo de trascendencia del fenómeno reformista, tanto desde el punto de vista de la deslocalización geográfica como de la conexión con sectores no universitarios.

[11] En el archivo de la mencionada escuela se encuentra la documentación probatoria de esta aseveración.

[12] Cabe aclarar que en 1931 el gobierno dictatorial de Ibáñez aprobó por decreto el voto femenino en elecciones municipales, pero fue en 1934 que se dictó la ley correspondiente.

[13] Mi agradecimiento a Marlenne Barrios Merino de la Coordinación Ejecutiva del libro, a quien envié algunos datos y de quien recibí luego abundantes pistas para mi trabajo.

[14] El Frente Popular se constituyó el 6 de mayo de 1936 respondiendo a una propuesta de lucha anti fascista-impulsada por los Partidos Comunistas-que ya se estaba dando en algunos países europeos y de América. En general fueron coaliciones amplias de partidos de izquierda y de fuerzas progresistas; en el caso de Chile lo integraron el Partido Comunista y el Partido Radical. Dos años más tarde, frente a la inminente elección presidencial, adhiere el Partido Socialista que debió resignar su candidato propio y aceptar la candidatura de Pedro Aguirre Cerda.

[15] Reglamento de Organización de la Acción de Mujeres Socialistas, en Estatuto y Reglamento del Partido Socialista (1939).

[16] Esto había ocurrido en Europa durante la guerra de 1914-1918.

[17] Lo había hecho extensamente en el artículo titulado «La reforma educacional en Austria» publicado por la Revista de la Universidad Nacional de Córdoba (Dellavale, 2016).

[18] La Caja del Seguro Obrero Obligatorio, organismo semi fiscal, fue creada en 1924 con aportes de los trabajadores contratados, sus empleadores y el Estado.

[19] La Opinión, 09/10/1939. Días después, en un extenso artículo la Confederación de Trabajadores de Chile se dirigía al Presidente Aguirre Cerda advirtiendo la superposición de funciones entre organismos similares dependientes de tres ministerios: del Interior, de Trabajo y de Salubridad con el exceso de burocracia que ello implicaba. Pedían que unificaran o al menos se coordinaran las acciones para hacerlas más eficientes. Destacaban asimismo la importante labor cultural y social que se realizaba a través del Departamento de Horas Libres - recordemos, dirigido por Leonilda Barrancos— de reciente creación (La Opinión, 18/10/1939).

[20] Revista Acción Social, 84.

[21] La Opinión, 19 de mayo de 1940.

[22] Magda Portal se ha caracterizado por una rebeldía que abarcaba todos los aspectos de su vida: en lo político integró el APRA porque adhería a ideas antioligárquicas y antiimperialistas y abogaba por los derechos de las mujeres, en lo profesional fue la primera mujer poeta de la corriente vanguardista, en fin, fue perseguida con saña por su militancia política y tal vez por desentonar con los estándares femeninos de la época. Uno de sus exilios lo cumplió en Chile coincidiendo con la presencia allí de Leonilda.

[23] La Opinión, 18/08/1943. 